Научная статья

УДК 159.9

DOI: $10.18101 / 2307-3330-2021-4-20-27$

\title{
РЕЗУЛЬТАТЫ ИССЛЕДОВАНИЯ СПОСОБНОСТЕЙ СТУДЕНТОВ К НАПИСАНИЮ ЭССЕ
}

\section{(C) Баяржаргал Бархас}

магистр, старший преподаватель,

Монгольский государственный университет образования

Институт дошкольного образования МГУО

Монголия, Улан-Батор

bayarjargal@msue.edu.mn

\section{(C) Мягмар Бямбажав}

магистр, преподаватель,

Монгольский государственный университет образования

Институт дошкольного образования МГУО

Монголия, Улан-Батор

miran@msue.edu.mn

\section{(C) Хажидмаа Дашням}

преподаватель,

Монгольский государственный университет образования

Институт дошкольного образования МГУО

Монголия, Улан-Батор

khajidmaa@msue.edu.mn

Аннотация. В статье рассматриваются результаты исследования по развитию способности студентов писать эссе. Эссе - это наиболее открытый вид выражения своего мнения на основе различных интеллектуальных действий, таких как анализ и изучение, наблюдение и размышление, детальная интерпретация, обобщенная оценка, сравнение, формулирование, прогнозирование и отождествление любых проблем с разных точек зрения, основанных на фактах. Таким образом, эссе является интересной формой самостоятельной работы студентов, поскольку оно обеспечивает определенную поддержку навыков писать кратко, лаконично, просто, ясно выражать мысли.

В рамках этого исследования представлены результаты анализа 50 эссе, написанных первокурсниками по специальности «дошкольное образование» во время выполнения самостоятельной работы. В работе представлен богатый материал, который раскрывает творческие идеи, предложения и размышления с использованием богатого наследия родного языка.

Keywords: самостоятельная работа студентов, письмо, грамотность, критерий, показатели, сочинение.

\section{Для цитирования}

Баяржаргал Б., Мягмар Б., Хажидмаа Д. Результаты исследования способностей студентов к написанию эссе // Вестник Бурятского государственного университета. Образование. Личность. Общество. 2021. № 3. С. 20-27. 

санию ЭССЕ

В пункте 1.3 долгосрочной политики развития Монголии «Видение 2050» сказано, что необходимо «создание среды монгольского языка, основанной на знаниях, и создание фонда для защиты богатого словарного запаса монгольского языка», а в пункте 1.3.2. отмечено, что необходимо «Устранить все виды ошибок и искажений в использовании монгольского языка и письменности, сделать для всех привычкой уважать и использовать свой родной язык и культуру, грамотно писать без ошибок на родном языке, а также публиковать новости и информацию, написанные на монгольском языке грамотно без ошибок в рамках социальной ответственности организаций и сообществ».

В соответствии с п. 19.1.1 Закона о монгольском языке, утвержденного в 2015 году, в связи с реализацией правил грамматики монгольского языка и положений о строгом соблюдении норм монгольского языка в современной литературе, надлежащим образом ставится вопрос о том, что студенты должны уважать свою родную культуру, уметь писать без грамматических и стилистических ошибок, выражать свои идеи в упорядоченном и логическом порядке и подходить к написанию источников.Одна из форм для студентов учиться самостоятельно и применять то, чему научились, - это размышление, исследование, наблюдение, ведение записи и написание эссе. Эссе можно считать распространенным видом написания и обучения студентов, поскольку оно по своей структуре занимает промежуточное положение между официальным письмом, исследованиями, литературой и статьей.

\section{Результаты исследования}

Обучение в университете - это активный процесс предоставления качественного образования посредством обучения, ориентированного на студентов, который поощряет их творческое участие, что измеряется качеством самостоятельных работ, выполняемых студентами. Акцент делается на творческом участии студентов в повышении качества и эффективности домашних заданий и на развитии отношения, которое побуждает их учиться все больше и больше, вдохновляя их на прогресс в своих знаниях и навыках. Подчеркивание важности творческого участия студентов в повышении качества и эффективности самостоятельных работ, а также придание им уверенности в том, что они будут воодушевлены своим прогрессом и успехами и будут усерднее учиться, имеют значительный эффект для повышения качества и эффективности самостоятельных работ студентов

Была выбрана дисциплина, входящая в учебную программу специальности «Педагог дошкольного образования» Монгольскогого сударственного университета образования, и было проведено исследование форм самостоятельных работ студентов, способностей студентов читать, писать, обрабатывать и размышлять над материалами, выражать собственные мысли в ходе выполнения самостоятельной работы по следующим критериям и показателям.

Как показано в таблице 1 , критерии по оценке эссе, которые являются формой самостоятельных работ студента, оцениваются по шкале от 1 до 4: во вводной части эссе оценивается способность проникнуть в суть проблемы и затрагивать проблему; критерием 2 оцениваются, основано ли эссе на фактах, внутренная логика, взаимосвязь и преемственность, по которой которая постепенно переходит от одного вопроса к другому; критерием 3 оценивается соответствие текста 
требованиям, критерием 4 оценивается, включен ли источник, использованный для написания эссе, и как отражено мнение в выводе.

Таблица 1

Критерий для проверки навыков написания эссе

\begin{tabular}{|c|c|c|}
\hline Критерий & Показатели & Балл \\
\hline \multirow{4}{*}{$\begin{array}{l}\text { Введение или начальная } \\
\text { часть, затрагивающая } \\
\text { проблему }\end{array}$} & $\begin{array}{l}\text { Интересное и оптимальное введение или начальная часть, } \\
\text { затрагивающая проблему. }\end{array}$ & 4 \\
\hline & $\begin{array}{l}\text { Есть введение или начальная часть, затрагивающая } \\
\text { проблему. }\end{array}$ & 3 \\
\hline & Затронутая проблема не ясна и носит общий характер & 2 \\
\hline & $\begin{array}{l}\text { Есть введение, но проблема не затронута должным обра- } \\
\text { зом. }\end{array}$ & 1 \\
\hline \multirow{4}{*}{$\begin{array}{l}\text { Опора на факты, } \\
\text { внутреннюю логику, } \\
\text { согласованность, } \\
\text { преемственность }\end{array}$} & $\begin{array}{l}\text { Факты, доказательства, новые данные, информация и ци- } \\
\text { таты достаточны и правильны, логическая последователь- } \\
\text { ность и взаимосвязь превосходны }\end{array}$ & 4 \\
\hline & $\begin{array}{l}\text { Факты, доказательства, новые данные, информация и ци- } \\
\text { таты включены правильно, в логической последователь- } \\
\text { ности и взаимосвязанны. }\end{array}$ & 3 \\
\hline & $\begin{array}{l}\text { Факты, доказательства, новые данные, информация и ци- } \\
\text { таты недостаточные, логическая последовательность и } \\
\text { взаимосвязь слабы. }\end{array}$ & 2 \\
\hline & $\begin{array}{l}\text { Мало фактов, доказательств, новых данных и информа- } \\
\text { ции, содержание не соответствует теме. }\end{array}$ & 1 \\
\hline \multirow{4}{*}{$\begin{array}{l}\text { Соблюдение требований } \\
\text { стилистики и грамма- } \\
\text { тики }\end{array}$} & Нет стилистических и грамматических ошибок & 4 \\
\hline & Несколько стилистических и грамматических ошибок & 3 \\
\hline & $\begin{array}{l}\text { Ошибочная точка зрения стилистики, но смысл текста } \\
\text { понятен }\end{array}$ & 2 \\
\hline & $\begin{array}{l}\text { Много грамматических ошибок, стилистика текста } \\
\text { недостаточная }\end{array}$ & 1 \\
\hline \multirow[t]{4}{*}{ Источники и выводы } & $\begin{array}{l}\text { Отразил свои идеи, используя примеры, факты и } \\
\text { соответствующие источники }\end{array}$ & 4 \\
\hline & $\begin{array}{l}\text { Были использованы примеры, факты и соответствующие } \\
\text { источники, но не отразил свои идеи }\end{array}$ & 3 \\
\hline & $\begin{array}{l}\text { Нет примеров, фактов или соответствующих источников, } \\
\text { но сделаны выводы }\end{array}$ & 2 \\
\hline & $\begin{array}{l}\text { Неправильный выбор используемого источника или ис- } \\
\text { точник не указан }\end{array}$ & 1 \\
\hline
\end{tabular}

В начале оценивания, по результатам исследования введения или начальной части, затрагивающей проблему, процент студентов, выполнивших ту часть эссе, в которой затрагивалась проблема и четкое представление введения, составлял 40 процентов. 
Б. Баяржаргал, Б. Мягмар, Д. Хажидмаа. Результаты исследования способностей студентов к написанию ЭССЕ

\begin{tabular}{lcc}
\hline & \multicolumn{2}{c}{ Таблица 2 } \\
\hline \multicolumn{1}{c}{ Введение или начальная часть, затрагивающая проблему } & Частота & В \% \\
\hline $\begin{array}{l}\text { Интересное и оптимальное введение или начальная часть, } \\
\text { затрагивающая проблему }\end{array}$ & 15 & 30 \\
\hline Есть введение или начальная часть, затрагивающая проблему & 20 & 40 \\
\hline Затронутая проблема не ясна и носит общий характер & 10 & 20 \\
\hline Есть введение, но не смог осветить проблему должным образом & 5 & 10 \\
\hline Итого & 50 & 100 \\
\hline
\end{tabular}

Во вводной части 30 процентов всех студентов интересно начали эссе и описали, как они видят проблему, 40 процентов определили основную проблему в эссе и соответствовали критериям, а 10-20 процентов не смогли увидеть проблему, и затронтутые ими проблемы были неуместными. Это указывает на то, что учащимся необходимо сосредоточиться на определении проблемы и их решении.

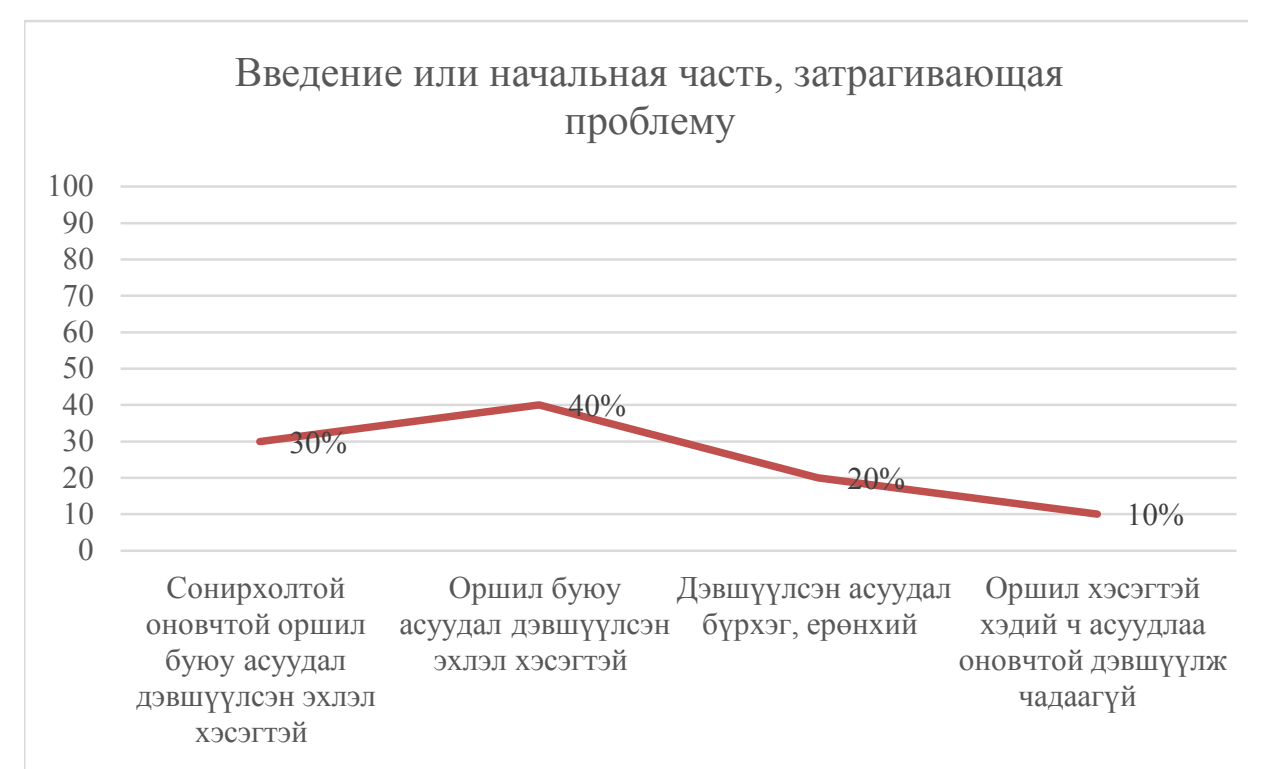

Рис. 1

По результатам исследования критерия 2 об обоснованности фактов и внутренних взаимосвязей, 50 процентов студентов определили логическую взаимосвязь данных и информации, но оставшиеся 50 процентов не предоставили логическую взаимосвязь и решения для эссе, что указывает на важность дальнейшего сосредоточения внимания на выявлении внутренней взаимосвязи и последовательности в тексте, соответствие между темой и содержанием.

Как показано в таблице 3 , по результатам оценки, как отражается реальность, основанная на фактах, и внутренняя взаимосвязь, неполные доказательства и цитаты в эссе, а также неспособность установить логическую взаимосвязь были самыми высокими т.е. 38\%; не включение никаких данных и информации или фактов, относящихся к теме, составляет 12 процентов; отражение фактов и 
доказательств, а также достаточное отражение взаимосвязи темы в последовательности составляет 50 процентов.

Таблица 3

\begin{tabular}{lcc}
\hline Основаны на фактах, внутренней логике, согласованности, преемственности & $\begin{array}{l}\text { Ча- } \\
\text { стота }\end{array}$ & Процент \\
\hline $\begin{array}{l}\text { Факты, доказательства, новые данные, информация и цитаты доста- } \\
\text { точны и правильны, логическая последовательность и взаимосвязь } \\
\text { превосходны }\end{array}$ & 13 \\
\hline $\begin{array}{l}\text { Факты, доказательства, новые данные, информация и цитаты вклю- } \\
\text { чены правильно, в логической последовательности и взаимосвязанны }\end{array}$ & 12 & 24 \\
\hline $\begin{array}{l}\text { Факты, доказательства, новые данные, информация и цитаты } \\
\text { недостаточно обоснованы, логическая последовательность и } \\
\text { взаимосвязь слабы }\end{array}$ & 19 & \multirow{2}{*}{38} \\
\hline $\begin{array}{l}\text { Мало фактов, доказательств, новых данных и информации, содержа- } \\
\text { ние не соответствует теме }\end{array}$ & 6 & \\
\hline Итого & 50 & 12 \\
\hline
\end{tabular}

Основанность на фактах, внутренняя логика, согласованность, преемственность

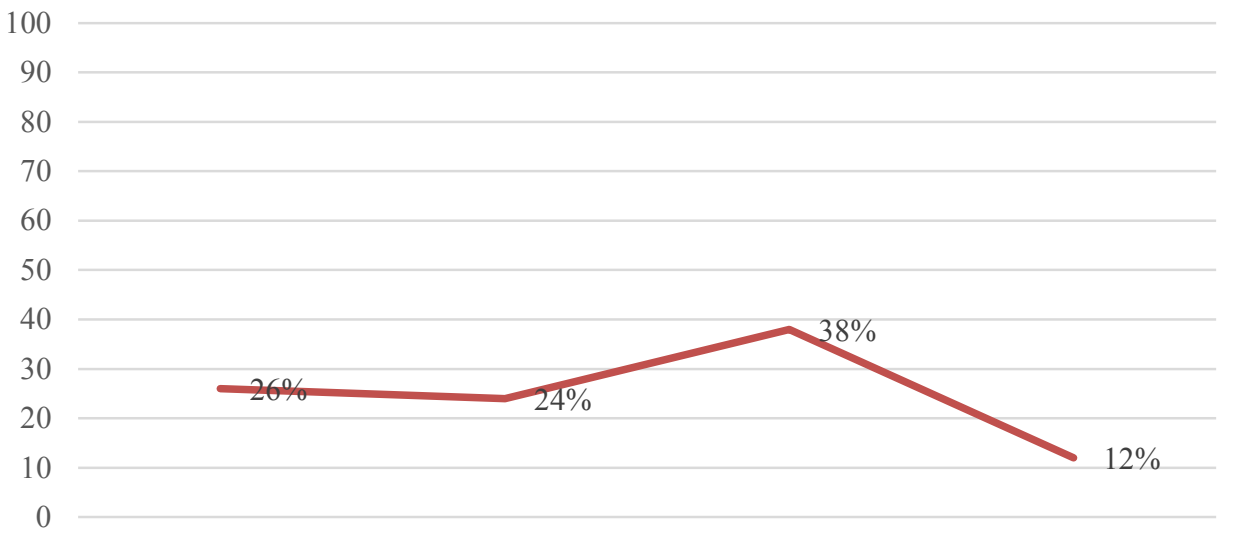

Рис. 2

Таблица 4

\begin{tabular}{|l|c|r|}
\hline Соблюдение требований стилистики и грамматики & Частота & Процент \\
\hline Нет стилистических и грамматических ошибок & 11 & 22 \\
\hline Несколько стилистических и грамматических ошибок & 16 & 32 \\
\hline $\begin{array}{l}\text { Ошибочность точки зрения стилистики, но смысл текста } \\
\text { понятен }\end{array}$ & 15 & 30 \\
\hline $\begin{array}{l}\text { Много грамматических ошибок, стилистика текста } \\
\text { недостаточная }\end{array}$ & 8 & 16 \\
\hline Итого & 50 & 100 \\
\hline
\end{tabular}


Б. Баяржаргал, Б. Мягмар, Д. Хажидмаа. Результаты исследования способностей студентов к написанию ЭССЕ

\section{Соблюдение требований стилистики и грамматики}

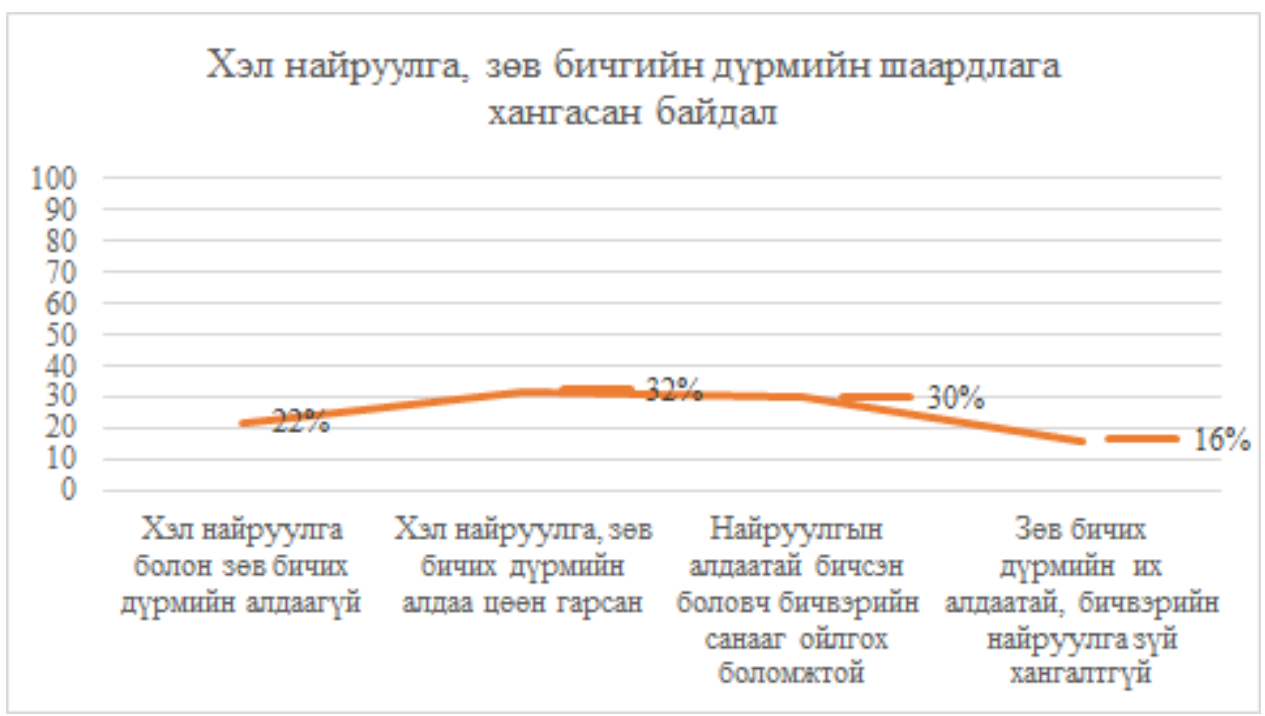

Рис. 3

Как показано в таблице 4, критерий 3 показывает, что, если оценить соответствие требованиям грамматики и стилистики монгольского языка, эссе с наименьшим количеством грамматических и стилистических ошибок составляют $32 \%$; эссе с стилистическими ошибками, но смысл текста передан составляют $30 \%$; эссе без грамматических и стилистических ошибок составляют $22 \%$; эссе с стилистическими недостатками и с большим количеством грамматических ошибок составляют $16 \%$.

Таблица 5

\begin{tabular}{lcc}
\hline \multicolumn{1}{c}{ Источники и выводы } & $\begin{array}{c}\text { Ча- } \\
\text { стота }\end{array}$ & $\begin{array}{c}\text { Про- } \\
\text { цент }\end{array}$ \\
\hline $\begin{array}{l}\text { Отразил свои идеи, используя примеры, факты и соответствующие } \\
\text { источники }\end{array}$ & 18 & 36 \\
\hline $\begin{array}{l}\text { Были использованы примеры, факты и соответствующие источ- } \\
\text { ники, но не отразил свои идеи }\end{array}$ & 15 & 30 \\
\hline $\begin{array}{l}\text { Нет примеров, фактов или соответствующих источников, но сде- } \\
\text { ланы выводы }\end{array}$ & 12 & 24 \\
\hline $\begin{array}{l}\text { Неправильный выбор используемого источника или источник не } \\
\text { указан }\end{array}$ & 5 & 10 \\
\hline Итого & 50 & 100 \\
\hline
\end{tabular}


Источники и выводы

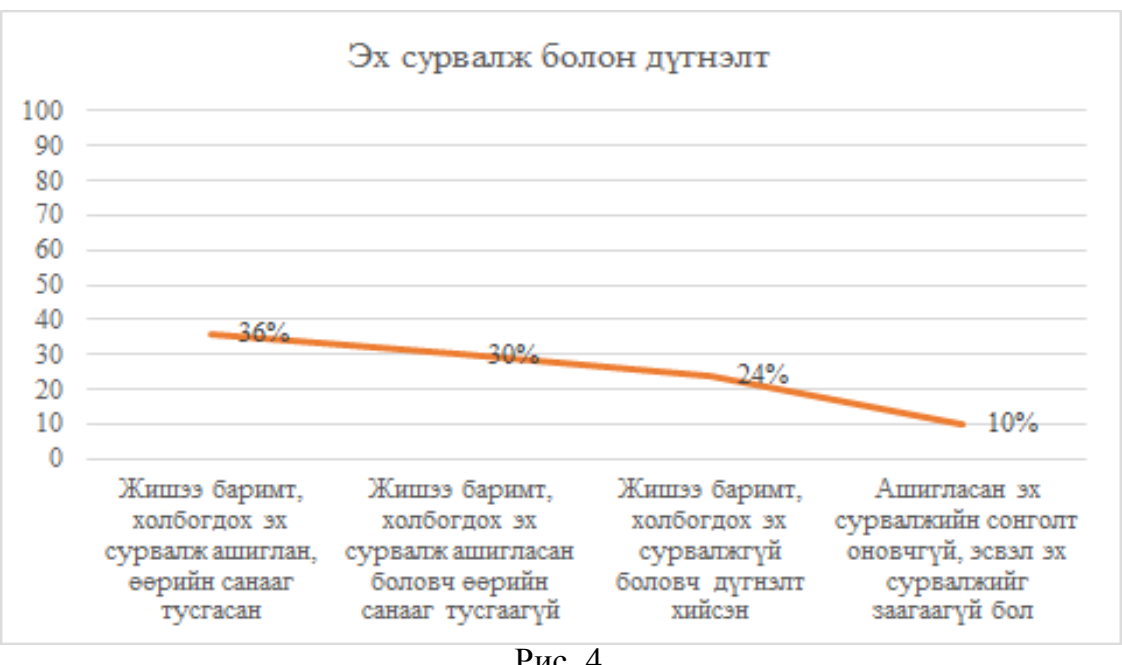

Рис. 4

Как показано в таблице 5, критерий 4 показывает, что эссе, в которых отражены идеи учащихся, с использованием примеров, фактов и соответствующих источников, составляет самый высокий, т.е. $36 \%$; эссе, в которых использованы примеры, факты и соответствующие источники, но не отражено собственное мнение, составляют $30 \%$; эссе, в которых нет примеров, фактов или соответствующих источников, но сделан вывод, составляют $24 \%$; эссе, в которых неправильный выбор используемого источника или источник не указан, составляет $10 \%$.

\section{Заключение}

По результатам исследования можно сделать следующие выводы.

1. Чтобы научиться писать эссе при выполнении самостоятельной работы, студенту необходимо научиться осуществлять поиск разнообразных источников информации, читать и изучать книги, руководства и материалы, делать заметки, писать в соответствии с грамматическими и стилистическими правилами, точно и правильно выражать свои мысли.

2. По результатам исследования можно сделать вывод о том, что студентам необходимо сосредоточиться на правильном и оптимальном определении и решении проблем, определении логических взаимосвязей между информацией, составлении выводов и установлении согласованности и преемственности между ними.

3. Важно обратить внимание на внутреннюю согласованность и взаимосвязь эссе, последовательность содержания и последовательность изложения темы.

4. Обучение информационного века требует от студентов реалистичной самооценки, проявления творческих подходов и развития творческого мышления.

Литература

1. Баттулга С. Стилистика монгольского языка. Улан-Батор: Фонд Бэмби. 2018. 240 с. Текст: непосредственный. 

санию ЭССЕ

2. Жадамбаа Б. Методология научно-исследовательских работ. Улан-Батор: Фонд Бэмби. 2001. 140 с. Текст: непосредственный.

3. URL: https://mfa.gov.mn/48800. Текст: электронный.

4. URL: https://legalinfo.mn/mn/detail/10932. Текст: электронный.

Статья поступила в редакичию 02.10.2021; одобрена после рецензирования 13.10.2021; принята к публикациии 15.12.2021.

\title{
RESULTS OF STUDY OF STUDENTS' ABILITIES TO WRITE ESSAY
}

Bayarjargal Barkhas

master, senior lecturer

Mongolian National University of Education, IDO

Ulan-Bator, Mongolia

bayarjargal@msue.edu.mn

Myagmar Byambaja

master, teacher

Mongolian National University of Education, IDO

Ulan-Bator, Mongolia

E-mail: miran@msue.edu.mn

\author{
Khajidmaa Dashnyam \\ teacher \\ Mongolian National University of Education, IDO \\ Ulan-Bator, Mongolia \\ khajidmaa@msue.edu.mn
}

The article discusses the results of the study of the ability of students to write an essay study in the specialty «Pre-school education». The paper presents a rich material that reveals creative ideas, suggestions and reflections using the rich heritage of the native language. Essay is the most open type of expression on the basis of various intellectual actions, such as analysis and study, observation and reflection, detailed interpretation, generalized assessment, comparison, formulation, forecasting and identifying any problems from different points of view based on facts. Thus, the essay is an interesting form of independent work of students, since it provides certain support for skills to write briefly, concisely, simply, to express thoughts.

Within the framework of this study, the results of the analysis of 50 essays written by firstyear students are presented in the specialty of preschool age during independent work.

Keywords: independent work of students, letter, letter ability, criterion, indicators, composition.

The article was submitted 02.10.2021; approved after reviewing 13.10.2021; accepted for publication 15.12.2021. 